\title{
FUSIONES Y ADQUISICIONES: UN ENFOQUE ALTERNATIVO
}

MERGERS AND ACQUISITIONS: AN ALTERNATIVE APPROACH

\section{Beatriz Herrera García *}

Docente Principal de la Facultad de Ciencias Contables - UNMSM

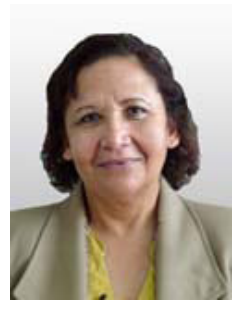

[Recepción: Agosto de 2011/ Conformidad: Octubre de 2011]

\section{RESUMEN}

En 2010 se observó una leve recuperación de las corrientes de inversión extranjera directa. Esta recuperación tiene lugar después de un descenso brusco de dichas corrientes de capital en todo el mundo. Como consecuencia de ese fenómeno y de la crisis mundial las fusiones y adquisiciones de empresas, a nivel global, han disminuido considerablemente durante los años 2008 y 2009. La principal razón tendría que ver con el efecto de la crisis económica que genera un descenso en la capacidad de las empresas para realizar operaciones de este tipo, sin embargo, se considera que bajo el escenario de incertidumbre internacional las fusiones y adquisiciones pueden convertirse en estrategias de crecimiento económico, dada la posibilidad de comprar empresas a precios relativamente bajos.

El menor dinamismo del mercado mundial está ocasionando una disminución del valor relativo de las empresas; sin embargo, en el mercado de América Latina que observa gran dinamismo, el proceso de fusiones $y$ adquisiciones ha tenido por objetivo las empresas manufactureras, las empresas de alimentos y bebidas y, las de servicios financieros.

Palabras clave: Inversión directa extranjera, adquisiciones, fusiones, pyme.

\begin{abstract}
In 2010 there was a slight recovery in foreign direct investment flows. This recovery takes place after such a sharp drop in capital flows worldwide. As a result of this phenomenon of global crisis and the mergers and acquisitions, globally, have declined over the years 2008 and 2009. The main reason had to do with the effect of the global crisis that generates a decline in the ability of firms to perform such operations. However, it is considered that underthe scenario of international uncertainty mergers and acquisitions can be converted into economic growth strategies, given the possibility of buying companies at relatively low prices.

The slowdown of the global market is causing a decline in the relative value of companies; however, in the Latin American market shows great dynamism, the process of mergers and acquisitionshas been to manufacturing companies, food companies and beverage, and then financial services.
\end{abstract}

Keywords: foreign direct investment, acquisitions, mergers, smes.

* Doctora en Ciencias Económicas - UNMSM. Ex- Vicerrectora Administrativas - UNMSM. Docente Investigadora de la Facultad de Ciencias Contables - UNMSM, Docente Principal de la Facultad de Ciencias Contables - UNMSM.

E- mail: bherrerag@unmsm.edu.pe 


\section{INTRODUCCION}

En un artículo anterior (ver, Fusiones \& Adquisiciones transfronterizas) afirmaba que la evolución del pensamiento económico hacia la libertad de los movimientos de capital en las décadas finales del S.XX, respondió a un cambio en la mentalidad económica. Resultaba lógico que la evolución del pensamiento económico haya entrañado un cambio en el planteamiento respecto a los movimientos de capital. Sin embargo, pronto la crisis financiera -en especial la crisis asiática de 1997-, puso de manifiesto, por una parte, que los movimientos de capital podrían jugar un papel decisivo en las futuras crisis monetarias $y$, por otra parte, podrían tener graves consecuencias en torno a la vulnerabilidad de los sistemas financieros. Fenómenos que han venido ocurriendo.

Las corrientes de inversiones extranjeras directas, fuentes de capital para llevar a cabo procesos de fusiones y adquisiciones de empresas a nivel global, han experimentado una fuerte contracción en el periodo 2008-2009, lo mismo ha ocurrido con todos los componentes de dichas corrientes de capital: inversiones en capital social; préstamos intraempresariales, y reinversión de utilidades.

En consecuencia, los bajos niveles de fusiones y adquisiciones transfronterizas (FAST), así como los menores beneficios de las filiales extranjeras, han tenido una grave repercusión en las inversiones de capital social y en la reinversión de utilidades.

Esa tendencia refleja los importantes cambios cuantitativos y cualitativos ocurridos a nivel mundial. Así, a inicios del nuevo milenio se registraron importantes cambios cuantitativos en los flujos de las inversiones extranjeras directas (IED) a nivel internacional, por ejemplo éstas llegaron a alcanzar los 800,000 millones de dólares en 1999, colocándolas como motor fundamental de la economía mundial. Junto a ello se observaron tres cambios cualitativos: Primero, destaca el surgimiento de una corriente de inversiones denominadas outward (Fusiones y adquisiciones realizadas por grandes empresas de países en desarrollo para internacionalizar su producción). Estos flujos son aún minoritarios pero tienen la importancia de indicar una nueva tendencia en las corrientes de capital. Segundo, a inicios del nuevo milenio se comprobó un gran auge en las $\mathrm{FAST}_{\mathrm{T}}$ como modalidad de las corrientes de inversiones directas extranjeras a nivel mundial. En los países desarrollados se convirtieron en modalidad dominante dentro de este tipo de inversión, bajo el impulso de la reestructuración en algunas industrias como la automotriz, telefonía, banca, químicos, etc. Tercero, es un cambio referente a la dinámica de las $\mathrm{FAS}_{\mathrm{T}}$ у las interrelaciones entre lo que ocurre en el nivel sectorial global y los mercados nacionales.

Históricamente las fusiones y adquisiciones han tenido un carácter cíclico, que se inicia desde fines del S. XX con los procesos de éste tipo ocurridos en la economía norteamericana; luego, se observan dos movimientos en esa modalidad de inversión: la primera, transcurrió en el periodo 1988-1990 y, la segunda, que se inicia en 1995. Sin embargo, los ciclos actuales difieren cualitativamente de aquellos ocurridos en el pasado. De una parte, porque se trata de movimientos internacionales de compra y venta de empresas que ocurren tanto entre países desarrollados como desde éstos hacia los países en desarrollo y desde éstos últimos hacia otros países del mismo tipo y aún hacia los países desarrollados. De otra parte, porque junto con estos procesos que se cumplen en ámbitos nacionales se concretan en lo que se denomina como fusiones y adquisiciones globales, que son aquellas realizadas en industrias globales. Esto indica que tiende a generarse un mercado mundial de empresas. 


\section{TENDENCIAS RECIENTES}

En el año 2010 se observó cierta recuperación de las corrientes de inversión directa extranjera. Esta recuperación tiene lugar después de una reducción brusca de dichas corrientes de capital en todo el mundo durante 2009. Es decir, se produjo una caída espectacular, luego de descender un 16 por ciento en 2008, las entradas mundiales de inversiones directas extranjeras volvieron a disminuir otro 37 por ciento en 2009, mientras que las salidas de dichas corrientes de capital se redujeron en ese año alrededor del 43 por ciento. Ello se debió a cambios ocurridos en la economía mundial.

Primero, está previsto que siga aumentando el peso relativo de las economías en desarrollo y economías en transición como países de destino y origen de las inversiones extranjeras directas mundiales (en 2005 absorbieron casi la mitad de las entradas de las inversiones extranjeras directas.

Segundo, no es probable una reversión del reciente nuevo descenso de las inversiones extranjeras directas destinadas al sector manufacturero, en comparación con las destinadas al sector de los servicios y al sector primario.

Tercero, a pesar de la fuerte repercusión en las corrientes de inversión extranjera directa (IED), la actual crisis no ha frenado la creciente internacionalización de la producción.

Así,los procesos de fusiones y adquisiciones (FAS), que en 2009 no habían superado los 250,000 millones de dólares, aumentaron un 36 por ciento durante la primera mitad de 2010 -en comparación a similar periodo del año anterior-.

La mayor parte del descenso de la inversión extranjera directa (IED) en 2009, se explica por la disminución de las fusiones y adquisiciones (FAS). Las adquisiciones en el extranjero experimentaron una contracción del 34 por ciento (un $65 \%$ en valor) en comparación con la reducción del 15 por ciento registrada en el número de proyectos de IED en inversiones en nuevas instalaciones. Las FAS suelen ser más sensibles a las condiciones financieras que los proyectos en nuevas instalaciones. Ello se debe a que las turbulencias de los mercados bursátiles impiden ver las señales de los precios en que se basan las FAS, y a que los ciclos de inversión de las FAS suelen más breves que los de las inversiones en nuevas instalaciones. La crisis mundial recortó la financiación disponible para las IED, reduciendo el número de adquisiciones.

La disminución de las corrientes de capital (IED) abarco a los tres sectores de la economía: el primero, el sector manufacturero y el de los servicios. Las industrias cíclicas como la automotriz y las químicas no fueron las únicas afectadas. Las inversiones extranjeras directas en industrias que en un principio habían resistido bien la crisis económica y financiera, como las farmacéuticas y las de elaboración de alimentos, también se desplomaron en 2009. Tan sólo un pequeño número de industrias recibieron más corrientes de capital (IED) en ese año que en el anterior (i.e., las de distribución de electricidad, gas y agua, así como las de aparatos electrónicos,, la construcción y las de telecomunicaciones). En total, la más afectada fueron las inversiones extranjeras directas para el sector manufacturero, que reflejo una disminución del 77 por ciento en las fusiones y adquisiciones transfronterizas $(\mathrm{FAS} \mathrm{T}$ ) en comparación con el año anterior (2008). La contracción de esas operaciones en el sector primario y en el sector de los servicios fue menos grave, un 47 por ciento y un 57 por ciento, respectivamente. De esta manera continuó aumentando el peso relativo en las FAS ${ }_{\text {T }}$ mundiales a expensas del sector manufacturero. 
Cuadro 1

Corrientes de capital (IED) por regiones, 2007-2009

(En miles de millones de dólares)

\begin{tabular}{|c|c|c|c|c|c|c|}
\hline & \multicolumn{3}{|c|}{ Entradas de IED } & \multicolumn{4}{c|}{ Salidas de IED } \\
\hline Región & 2007 & 2008 & 2009 & 2007 & 2008 & 2009 \\
\hline Total mundial & 2100 & 1771 & 1114 & 2268 & 1929 & 1101 \\
\hline Econom.desarroll & 1444 & 1018 & 566 & 1924 & 1572 & 821 \\
\hline Econom.endesarr & 565 & 630 & 478 & 292 & 296 & 229 \\
\hline Africa & 63 & 72 & 59 & 11 & 10 & 5 \\
\hline A.Latina & 164 & 183 & 117 & 56 & 82 & 47 \\
\hline Asia Oc & 78 & 90 & 68 & 47 & 38 & 23 \\
\hline Asia $* *$ & 259 & 282 & 233 & 178 & 166 & 153 \\
\hline Europa S. y CEI * & 91 & 123 & 70 & 52 & 61 & 51 \\
\hline
\end{tabular}

Fuente.- UNCTAD, World Investment Report (WIR), 2010

${ }^{*}$ Comprende toda Europa Sudoriental y la Comunidad de Estados Independientes

${ }^{* *}$ Comprende Asia Meridional, Asia Oriental y Asia Sudoriental

En el Cuadro 1 se puede observar como todas las corrientes de capital (entrada y salidas) registran fuertes reducciones afectadas por la crisis mundial.

A consecuencia de las turbulencias económicas y financieras, las IED destinadas a América Latina se redujeron a 117,000 millones de dólares (ver, Cuadro 1), lo que supuso un descenso del 36 por ciento con respecto a 2008. Aunque Brasil, que absorbió un 42 por ciento menos de inversiones extranjeras resultó más afectado que el conjunto de la región, siguió siendo el principal receptor de IED. Las FAST de la región cayeron drásticamente y registraron números negativos en 2009 debido a las ventas de filiales extranjeras a empresas nacionales, sobre todo en el Brasil.

Las corrientes de IED destinadas a Asia Meridional, Oriental y Sudoriental han registrado su mayor descenso desde 2001 (ver, Cuadro 1). En 2009 las entradas de IED en la región bajaron un 17 por ciento a 233,000 millones de dólares, debido a la disminución de las $\mathrm{FAST}_{\mathrm{T}}$, que fue particularmente pronunciada en el sector servicios. El total de las salidas de IED de la región se redujo al- rededor del 8 por ciento pasando a 153,000 millones de dólares, y las FASт decayeron en un 44 por ciento. Las inversiones Chinas en el sector no financiero extranjero, en cambio, siguieron creciendo, impulsadas por la persistente búsqueda de recursos minerales y de oportunidades de FAS creadas por la reestructuración de la industria mundial.

En el Asia Oriental y Sudoriental la IED ya ha empezado a repuntar, dado que la región se encuentra a la vanguardia de la recuperación de la economía mundial. Las entradas de IED en China y la India, empezaron a aumentar ya a mediados de 2009; se prevé que en los años siguiente las salidas continuas d de IED de esos países. Permitirán reanudar el crecimiento de las inversiones de la región en el extranjero.

Tras ocho años de tendencias alcistas, las entradas de IED en Europa Sudoriental y la Comunidad de Estados Independientes (CEI) se redujeron a 70,000 millones de dólares (ver, Cuadro 1), una disminución del 
43 por ciento con respecto a 2008 . En ambas subregiones, las entradas de IED disminuyeron en 2009. Con todo en ese año Rusia se situó en el sexto lugar de la lista de mayores receptores. Las FAST se desplomaron debido a la ralentización de las adquisiciones de empresas por inversores de la Unión Europea $(\mathrm{UE})^{1}$, los mayores de la región.

Analizando las nuevas tendencias de la economía mundial se observa que en 2009, entre las mayores receptoras de las corrientes de capital (IED) se encuentra China, que pasó a ocupar el segundo lugar después de los Estados Unidos, desplazando al Reino Unido. La mitad de los seis principales países de destino de las corrientes de IED son en la actualidad economías en desarrollo o economías en transición. Más de las dos terceras partes de las $\mathrm{FAS}_{\mathrm{T}}$ todavía tienen lugar en países desarrollados.

En lo que respecta al origen de las inversiones extranjeras directas, Hong Kong, China y Rusia, en ese orden, figuran entre las 20 mayores inversoras a nivel global.

En América Latina, Brasil y México siguen gozando de la preferencia de los inversores extranjeros.

Por otro lado, las adquisiciones transfronterizas realizadas por empresas transnacionales (ETN) de la región, se da principalmente en países desarrollados, aumentando éstas un 52 por ciento, cifrándose en 3,700 millones de dólares- El desarrollo de las empresas transnacionales de la región, que empezó en 2003 impulsará las corrientes de IED en el extranjero a mediano plazo. Asimismo, las salidas de IED de la región latinoamericana pasaron de una media de 15,000 millones de dólares anuales en el periodo 1991-2000 a 48,000 millones de dólares anuales en el periodo 2003-2009. Un grupo creciente de empresas brasileñas y mexicanas se han ido expandiendo fuera de la región, orientándose sobre todo hacia economías desarrolladas.

\section{LAS FAS A COMIENZOS DEL MILENIO}

Los países desarrollados atrajeron 636,000 millones de dólares en 1999 de inversiones extranjeras directas, casi las tres cuartas partes del total mundial. Los Estados Unidos y el Reino Unido ocuparon los dos primeros lugares como inversores y receptores a la vez $^{2}$.

Las grandes operaciones de FAS que se llevaron a cabo en los Estados Unidos, impulsadas por el vigor continuado de su economía, lo convirtieron en el mayor receptor de IED en el 2000, con un aumento de 276,000 millones de dólares, casi la tercera parte del total mundial ${ }^{3}$. En cambio, las corrientes de IED hacia China que habían superado los 40,000 millones de dólares durante cuatro años consecutivos, cayeron aproximadamente un 8 por ciento en 1999.

Las FASt que se negocian en el mercado mundial emergente de empresas, han sido el factor principal que impulsó el aumento de IED en 1999-2000.

A lo largo de la década de los noventa el crecimiento de la producción mundial se ha debido principalmente a las $\mathrm{FAS}_{\mathrm{T}}{ }^{4}$ (incluidas las adquisiciones por inversores extranjeros de empresas públicas privatizadas), más que a las inversiones en nuevas instalaciones, el valor de las FASт llevadas a cabo, aumentó de menos de 100,000 millones de dólares en 1987 a 720,000 millones de dólares en 1999. Es decir, independientemente de si las inversiones extranjeras directas se destinan a nuevas instalaciones o a operaciones de FAS, lo cierto en que hicieron aumentar el volumen de la producción mundial. En ese periodo menos del 3 por ciento del total de FAS ${ }_{\text {T fue- }}$ ron clasificadas oficialmente como fusiones $y$ el resto fueron como adquisiciones. 
Las adquisiciones del 100 por ciento del capital de las empresas suman las dos terceras partes del número total de adquisiciones transfronterizas. Las adquisiciones minoritarias (de 10 a 49\% del capital) representaron alrededor de una tercera parte de las adquisiciones transfronterizas en los países en desarrollo, en comparación con menos de una quinta parte en los países desarrollados.

A fines de la década de los noventa, la mayoría de las FAS obedecieron a motivos estratégicos y económicos más que a motivos financieros inmediatos, en cambio a finales de la década de los ochenta muchas de las FAS estuvieron motivadas por la búsqueda de ganancias financieras a corto plazo. Por lo que a lo largo de los años 90's se observaron dos grandes oleadas de FAS: una en el periodo 1988-1990 y; otra desde 1995 en adelante. Esta última oleada ha ocurrido paralelamente al auge de las FAS internas, facilitadas por los créditos bancarios tradicionales y por la mayor utilización de instrumentos financieros tales como: la emisión de acciones ordinarias, canje de acciones o la emisión de deuda por las empresas (bonos corporativos), así como otra fuente de financiación ha sido los fondos de capital de riesgo, que ha permitido a muchas nuevas empresas o a pequeñas y medianas empresas (PYMEs) llevar a cabo procesos de fusiones y adquisiciones.

\section{EL ENFOQUE TEORICO DE LAS FAS}

Para entender mejor el fenómeno de las FAS, se debe tener en cuenta tanto los motivos fundamentales por los que se hace una fusión o una adquisición, como los cambios que se producen en el entorno económico, así como en su interacción.

En general, desde la perspectiva del inversor extranjero, las $\mathrm{FAS}_{\mathrm{T}}$ presentan dos grandes ventajas en comparación con las in- versiones extranjeras en nuevas instalaciones como modo de entrada de las IED: la rapidez y el acceso a activos patrimoniales.

El papel crucial que juega la rapidez en la vida de las empresas hace que las $\mathrm{FAS}_{\mathrm{T}}$ representan el medio más rápido de conquistar una posición sólida en un nuevo mercado y ganar poder de mercado (dominio sobre el mercado), sin aumentar el tamaño de las empresas ni repartir riesgos. Las FAST permiten a las empresas explotar las sinergias agrupando los recursos patrimoniales y las capacidades de las empresas que intervienen en estas operaciones, con posibles ganancias estáticas y dinámicas de eficiencia.

También otros motivos deben tenerse en cuenta al analizar las FAS, estos otros motivos tendrían que ver con los adelantos tecnológicos, la liberalización y los cambios que se producen en los mercados de capitales. El rápido ritmo de los adelantos tecnológicos ha acentuado las presiones sobre las empresas tecnológicas líderes mundiales para competir, que suelen ser empresas transnacionales (ETN). Al fusionarse con otras ETN que tienen capacidades complementarias, las empresas pueden repartirse los costos de las innovaciones, tener acceso a nuevos activos tecnológicos y mejorar su competitividad.

Las medidas de liberalización del comercio y de integración regional han dado un nuevo impulso a las FAST, al sentar las bases para una competencia más intensa y empujar a la reestructuración y consolidación a escala regional de la actividad empresarial. A su vez, la liberalización de los mercados de capitales y la proliferación de nuevos métodos de financiar estas operaciones han facilitado también a las FAST.

La oleada ocurrida en los años 90's de reestructuraciones empresariales a escala mundial y regional como resultado de las $\mathrm{FAS}_{\mathrm{T}}$ indican, que existe una relación diná- 
mica entre los factores fundamentales que empujan a las empresas a realizar fusiones y adquisiciones, con el fin de alcanzar sus objetivos estratégicos y enfrentar los cambios en el entorno económico mundial.

En el mercado de empresas las que no crezcan y obtengan beneficios estarán expuestas a sanciones. Una de esas sanciones es la de ser absorbida por otra empresa. Todos los motivos fundamentales, que empujan a las empresas a efectuar $\mathrm{FAS}_{\mathrm{T}}$ se combinan hasta convertirse en elementos esenciales del objetivo estratégico dominante, que es defender y mantener su competitividad en el mercado. Las FASт ofrecen a las empresas el camino más rápido para adquirir activos tangibles e intangibles en distintos países y les ayudan a reestructurar sus operaciones a escala nacional o mundial con el fin de explotar las sinergias y obtener ventajas estratégicas.

A finales de la década de los noventa, la industria automotriz, la de productos químicos y farmacéuticos, y los alimentos, las bebidas y el tabaco fueron las industrias del sector manufacturero en las que hubo una mayor actividad de FAS a escala mundial. La mayor parte de las FAS que se llevaron a cabo en esas industrias fueron de tipo horizontal (véase infra) y con ellas se buscaba obtener economías de escala, explotar sinergias tecnológicas, aumentar el poder de mercado, eliminar el exceso de capacidad o consolidar y racionalizar las estrategias de innovación y los presupuestos de investigación y desarrollo (I\&D). En la mayoría de las industrias en las cuales se ha efectuado una intensa actividad de operaciones horizontales de FAS han aumentado los índices de concentración.

En la industria automotriz, las FAS entre fabricantes y distribuidores ha dado origen a una mayor integración vertical. Las telecomunicaciones, la energía y los servicios financieros fueron las ramas del sector servi- cios en las que hubo una mayor actividad de FAS, y en gran parte como consecuencia de las medidas de desregulación y liberalización de tales ramas de los servicios ocurridas en los años noventa.

En los países en desarrollo, la repartición sectorial de las $\mathrm{FAS}_{\mathrm{T}}$ difiere considerablemente según se trate de la Unión Europea o de los Estados Unidos. En la UE las industrias de productos químicos, de alimentación, las bebidas y el tabaco son las industrias más buscadas por las empresas extranjeras para realizar operaciones de FAS.

En los Estados Unidos, las industrias preferidas son la industria eléctrica y de material electrónico y la industria química. En América Latina las operaciones de FAS se concentraron en los servicios públicos, el sector financiero, los productos del petróleo, el transporte, el de almacenamiento y las comunicaciones.

Similar a lo que ocurre con el proceso de mundialización, las FAS tienen un impacto de "doble filo" y "desarrollo desigual"s. En efecto, las FAST, y la expansión del mercado mundial en el que se compran y venden la propiedad y el control de empresas, suscitan ciertos interrogantes acerca de la balanza de beneficios y costos que suponen para los países receptores. Con la mundialización y los cambios rápidos que acarrea, son las empresas transnacionales (ET) las que se benefician exageradamente, mientras que las PYMEs locales de los países en desarrollo resultan perjudicadas. En ese sentido, las FAS, y sobren todo las de carácter transfronterizo, se presentan como un instrumento para la expansión de la gran empresa.

\section{TIPOLOGIA DE LAS FAS}

En términos generales las FAS son operaciones mediante las que se realiza la compra venta de derechos de propiedad y control sobre empresas. 
Fusión. Se produce una fusión cuando la adquisición de una empresa por otra desemboca en la absorción de la primera por la segunda o la consolidación de ambas en una nueva entidad bajo la propiedad y control del comprador. Es decir, se refiere a fusión cuando dos o más empresas deciden juntar sus patrimonios y formar una nueva empresa.

Adquisición. La adquisición se refiere a la compra de derechos de propiedad de una empresa por parte de otra empresa sin que la empresa adquirida quede incluida en la compradora. Esta puede ser una adquisición minoritaria cuando no supera al monto de acciones necesarias para lograr el control de la empresa o puede ser una adquisición mayoritaria cuando sí lo logra. Es decir, se refiere a adquisición cuando una empresa compra las acciones y/o activos patrimoniales de una empresa en número o valor suficientes para tener el control sobre la misma sin llevar a cabo la fusión de sus patrimonios.

En conjunto las FAS y la creación o ampliación de empresas constituyen dos modos básicos de la actividad de inversión, lo que puede ocurrir tanto dentro de un país, como entre países o a nivel de sectores de la economía global.

En el caso de las inversiones realizadas a nivel internacional como FAST, estas son una modalidad de IED alternativa a la denominada "greenfield" que representa el mencionado caso de creación o ampliación de una empresa en un país por parte de un inversionista extranjero. Es de advertir que las $\mathrm{FAS}_{\mathrm{T}}$ no significan, a corto plazo, nuevas inversiones sino un cambio de propietario entre empresas ubicadas en distintos países.

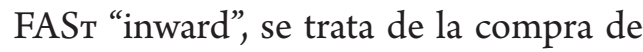
una empresa radicada en el exterior que realiza la compra de una empresa ubicada en el país. FASт "outward", son empresas nacionales que compran empresas ubicadas en el exterior.
FASт de tipo horizontal -entre empresas del mismo sector-, se da cuando comprando empresas en el mismo sector o campo de actividad, debido a la necesidad de ampliar su espacio de negocios e incrementar su tamaño con el fin de sostener posiciones frente a sus competidores, con la intención de participar en un mercado mayor o de las economías de escala. A este tipo de fusión también se le conoce como fusión estratégica. En el umbral del nuevo milenio, en términos de valor alrededor del 70 por ciento de las $\mathrm{FAS}_{\mathrm{T}}$ fueron de tipo horizontal.

FAST de tipo vertical se da cuando buscan integrar actividades hacia atrás o hacia adelante, internalizando procesos que mejoran sus costos o su competitividad. FAS entre empresas clientes y empresas proveedoras o entre empresas compradoras $\mathrm{y}$ empresas vendedoras.

FAS ${ }_{\mathrm{T}}$ heterógeneas, se da entre empresas de sectores sin relación alguna entre ellas.

Conglomerado, en este tipo de compañía la fusión o adquisición se realiza sólo buscando mejoras en la eficiencia y su consecuente sinergia. Dichas sinergias surgen de las ventajas que resultan de una actividad conjunta.

\section{CONCLUSIONES}

1. A corto plazo, las inversiones extranjeras directas (IED) destinadas para las FAS no siempre incrementan el equipo de capital para actividades de producción, cosa que si sucede cuando las IED se destinan para inversiones en nuevas instalaciones. En consecuencia, una determinada cantidad de IED que entra como resultado de una operación de FAS puede dar origen a una inversión productiva menor que la misma cantidad de IED en nuevas instalaciones. Sin embargo, si la única alternativa realista para una empresa local es el cierre, la fu- 
sión o adquisición transfronteriza puede servir de "salvavidas".

2. Las Inversiones extranjeras directas que entran a un país por una operación de FAS ofrecen menos posibilidades de que se transfiera tecnologías o conocimientos especializados menos o mejores que las IED en nuevas instalaciones. Además, pueden dar lugar directamente a la degradación o cierre de actividades locales de producción o funcionales (i.e., las actividades de investigación y desarrollo) o a su relocalización en función de estrategias empresariales del adquirente. Las IED en nuevas instalaciones no reducen directamente las capacidades y activos tecnológicos que pueda haber en la economía receptora.

3. Las inversiones extranjeras directas que son producto de una fusión o adquisición no crean empleo cuando entran en un país por la obvia razón de que una fusión o una adquisición no crean ninguna capacidad de producción nueva. Además, puede dar origen a despidos de personal. Las IED en nuevas instalaciones crean forzosamente nuevos puestos de trabajo al producirse la entrada de esas inversiones.

4. Las inversiones extranjeras directas que son producto de una fusión o una adquisición pueden aumentar la concentración del mercado del país receptor y producir resultados contrarios a la competencia; de hecho las FAS pueden utilizarse deliberadamente para reducir o eliminar la competencia. No obstante, estas inversiones pueden impedir que aumente la concentración si la absorción ayuda a salvar a una empresa local en graves dificultades. Las IED en nuevas instalaciones pueden por definición, incrementar el número de empresas existentes en el país receptor, pero no pueden aumentar directamente la concentración del mercado al producirse su entrada.

5. La cuestión básica que se plantea aquí es el del papel que deben jugar las empresas extranjeras en una economía nacional, al margen de si su entrada en ella se produce como resultado de una inversión en nuevas instalaciones o de una fusión o adquisición transfronteriza. Esta cuestión tiene que ver con el grado de propiedad extranjera que un país puede aceptar y con las consecuencias económicas, políticas, sociales y culturales de esa propiedad en manos extranjeras. La disyuntiva entre los objetivos económicos y los objetivos más generales de índole no económica, en particular, requieren juicios de valor que sólo los países pueden formular y adoptar.

1 El euro, la moneda de la UE, ha estabilizado los tipos de cambio contribuyendo a reducir los costos de transacción para los inversores de la región, pero también, ha acentuado la competencia, los que ha presionado más a las empresas para que reestructuren y consoliden sus operaciones.

2 En el 2000 las empresas transnacionales (ETN) ascendían a 63,000 empresas matrices y 690,000 filiales extranjeras, abarcando prácticamente a todos los países y actividades económicas. Las actividades de las filiales extranjeras se concentran principalmente en equipo electrónico y eléctrico, las automotrices, el petróleo, los productos químicos y los productos farmacéuticos.

3 El índice de transnacionalidad, que es una medida de la importancia de la participación de un país en la producción internacional, muestra la concentración de IED en pocos países (10 países recibieron el 74 por ciento de las corrientes mundiales de IED en 1999).

4 Pueden trazarse cierto paralelismo entre el auge de las FAS de los 90's y el que se produjo en Estados Unidos al final del Siglo XIX, que alcanzó su punto culminante entre 1898 y 1902. En ambas oleadas de FAS influyeron las grandes novedades tecnológicas, las nuevas formas de financiamiento y las modificaciones introducidas en la legislación reguladora.

5 En el centro de esa preocupación subyace la idea de que la adquisición de empresas nacionales por empresas extranjeras no aumenta la capacidad productiva del país, sino que supone simplemente una transferencia de propiedad y control de manos nacionales a manos extranjeras. Normalmente, estas transferencias suelen ir acompañadas de despido de trabajadores o del cierre de alguna actividad de producción o funcional si las empresas adquirientes son oligopolistas mundiales, pueden perfectamente llegar a dominar el mercado interior. Además, las FAS ${ }_{\mathrm{T}}$ pueden utilizarse deliberadamente para reducir la competencia en el mercado interior. Pueden tener bajo control del capital extranjero a empresas estratégicas o incluso sectores enteros (i.e., sectores clave como la banca), lo que es una amenaza para el desarrollo de la capacidad empresarial y la capacidad y tecnológica del país receptor. 


\section{REFERENCIAS BIBLIOGRÁFICAS}

1. Ballarín E., J. Canals y P. Fernández,Fusiones y adquisiciones de empresas. Un enfoque integrador, Alianza Editorial, Madrid, 1994.

2. Colaiácovo, L., et., al., Jointventures y otras formas de cooperación empresarial internacional, Cicome, Ediciones Macchi, Buenos Aires, 1992.

3. De Anzizu, J. M.,L. S. Vansina, P. H. Mirvis, et., al., Fusiones y adquisiciones: Análisis de casosreales, Documento de trabajo $\mathrm{N}^{\circ} 2$, Centre forOrganisationalStudies, Barcelona, 2000.

4. Garrido, Celso, Fusiones y adquisiciones transfronterizas en México durante los años noventa, Serie Desarrollo Productivo, Cepal, Santiago de Chile, 2001.

5. Guitian, M. y Varela, F., Los sistemas financieros ante la globalización, Universidad de Alcalá, España, 2000.

6. Herrera García, B., La conglomeración económica una vía de desarrollo para las PYMEs, Revista Quipukamayoc, UNMSM, Lima, 2003.
7. Herrera García, B., Fusiones \& adquisiciones transfronterizas, Revista Quipukamayoc, UNMSM, Lima, 2002.

8. Mascareñas Pérez-Iñigo, J., Manual de fusiones y adquisiciones, Mc Graw Hill, Madrid, 1993.

9. Mascareñas Pérez-Iñigo, J., Fusiones y adquisiciones de empresas, Mc Graw Hill, Madrid, 2000.

10. Matta María, J., Fusao e incorporacao de empresas, Editora MostreJou, Sao Paulo, 1972.

11. Mochón, Francisco y A. Rambla, La creación de valor y las grandes empresas españolas, Ariel Sociedad Economía, Barcelona, 1999.

12. Oman, Charles, Policy competition for foreign direct investment, DCS-OECD, París, 2000.

13. UNCTAD, Informe sobre las inversions en el mundo 2000, Naciones Unidas, Ginebra, 2000.

14. UNCTAD, World investment report (WIR) 2010, NacionesUnidas, Ginebra, 2010.

15. UNCTAD, Efectos de las corrientes de inversiones internacionales en el desarrollo, Naciones Unidas, Ginebra, 2001. 